\title{
New pH Correlations for Stainless Steel 316L, Alumina, and Copper(I) Oxide Nanofluids Fabricated at Controlled Sonication \\ Temperatures
}

\author{
Naser Ali ${ }^{1,2, a,{ }^{*}}$, Joao A. Teixeira ${ }^{1, b}$, and Abdulmajid Addali ${ }^{1, c}$ \\ ${ }^{1}$ Cranfield University, School of Aerospace, Transport and Manufacturing (SATM), \\ Cranfield, England, MK430AL, UK
}

${ }^{2}$ Nanotechnology and Advanced Materials Program, Energy and Building Research Center, Kuwait Institute for Scientific Research, Safat 13109, Kuwait

E-mail: ${ }^{a}$ nmali@kisr.edu.kw, ${ }^{\text {anaser.ali@cranfield.ac.uk, }}$ bi.a.amaral.teixeira@cranfield.ac.uk, ca.addali@cranfield.ac.uk

Keywords: Aluminium; Copper(I) oxide; Nanofluids; pH correlation; Stainless steel 316L.

\begin{abstract}
This research investigates the $\mathrm{pH}$ value of stainless steel (SS) 316L/ deionised water (DIW), alumina $\left(\mathrm{Al}_{2} \mathrm{O}_{3}\right) / \mathrm{DIW}$, and copper(I) oxide $\left(\mathrm{Cu}_{2} \mathrm{O}\right) / \mathrm{DIW}$ nanofluids prepared using a two-step controlled sonication temperature approach of $10^{\circ} \mathrm{C}$ to $60^{\circ} \mathrm{C}$. The nanoparticles volumetric concentration of each family of as-prepared nanofluid ranged from 0.1 to $1.0 \mathrm{vol} \%$, using as-received nanopowders, of $18-80 \mathrm{~nm}$ average particles size. Furthermore, the pH measuring apparatus and the measurement procedure were validated by determining the $\mathrm{pH}$ of

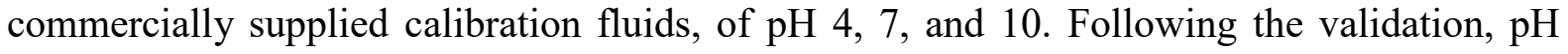
correlations were obtained from the experimental measurements of the $0.1,0.5$, and $1.0 \mathrm{vol} \%$ nanofluids in terms of varied sonication bath temperatures and volumetric concentrations. Those correlations were then combined into one robust $\mathrm{pH}_{\mathrm{nf}}$ correlation and validated using the $\mathrm{pH}$ data of the 0.3 and $0.7 \mathrm{vol} \%$ nanofluids. The new proposed correlation was found to have a $2.18 \%, 0.92 \%$, and $0.63 \%$, average deviation from the experimental $\mathrm{pH}$ measurements of SS $316 \mathrm{~L}, \mathrm{Al}_{2} \mathrm{O}_{3}$, and $\mathrm{Cu}_{2} \mathrm{O}$ nanofluids, respectively, with an overall prediction accuracy of $\sim 92 \%$.
\end{abstract}




\section{Introduction}

A new class of engineered fluids that rely on the dispersion of metals, metal oxides, allotropes of carbon, or a combination of any of these materials in the form of nanoparticles (NPs) of average diameter less than $100 \mathrm{~nm}$ and of low concentration, preferably $<1 \mathrm{vol} \%$, in a noncarcinogenic basefluid (e.g. water, oil, kerosene, glycols etc.) were defined by Choi in 1995 as 'Nanofluids' [1-3]. This advance category of fluids have gained the interest of many researchers due to their distinctive properties compared to conventional fluids in the field of heat transfer enhancement, drug delivery, paint additives, magnetic sealing, ionic liquid synthesis, etc [4-11]. Although significant research findings on the thermophysical properties of different nanofluids and their applicability are available in the literature, there is still a need for better understanding of the fluid stability behaviour $[12,13]$. To be more specific, the interaction between the NPs themselves and between the particles with the surrounding medium is still considered to be an area of exploration and of major concern. In general, nanofluids stability can be subclassified into dispersion stability, and kinetic stability [14]. Dispersion stability takes into account both the Van der Waals attraction force between the particles, and the electrostatic repulsion force caused by the electrical double layers on the particles surface, where clusters formation or agglomerations of particles are more likely to occur in a nanofluid when the attraction force is higher than the particle electrostatic repulsion force [15]. On the other hand, the kinetic stability describes the NPs dynamic Brownian motion in the basefluid, which causes particle sedimentation or phase-separation due to gravitational force [16]. The problem arising from the two aforementioned mechanisms is their negative impact on the long term stability of the suspensions if not appropriately dealt with, and hence can degrade the nanofluid thermophysical properties [17-19]. Basically, there are three main approaches to improve the stability of nanofluids: 1- sonicating the fluid, 2- adding surfactant, and 3-adjusting the $\mathrm{pH}$ value to optimize the zeta potential. Sonication, which is a physical method that depends on employing ultrasonic waves through the fluid, can be used to enhance the stability of the solution by rupturing the particles attractional force within the sediments [20]. Furthermore, using a surfactant of organic compounds that has hydrophilic head and hydrophobic tail group, has shown to be useful in increasing the stability of the aqueous solutions [21]. In addition, manipulating the $\mathrm{pH}$ value of nanofluids changes the NPs surface and can strongly improve the stability of the dispersed NPs [22, 23]. This is because the zeta potential, which is the potential difference between the layered fluid attached to the particles 
and the dispersed particles surface, can be increased/decreased by changing the $\mathrm{pH}$ value and/or adding surfactant to the nanofluid. In principle, zeta potential values of nanofluids above +30 $\mathrm{mV}$ or below $-30 \mathrm{mV}$ are considered to be more stable due to the high repulsive force generated between the charged NPs [24-26]. Implementing one or more of the aforementioned techniques can result in obtaining a more homogeneous and better dispersed nanofluid.

Several studies were undertaken to illustrate the influence of the $\mathrm{pH}$ value on the nanofluids stability [27-39]. For example, Manjula et al. [40] examined the effect of $\mathrm{pH}$ value and surfactants on the suspension behaviour of alumina $\left(\mathrm{Al}_{2} \mathrm{O}_{3}\right) / \mathrm{H}_{2} \mathrm{O}$ nanofluid via monitoring the formed sedimentations in the fluid. It was found that optimizing the $\mathrm{pH}$ value and adding surfactant to the nanofluid have resulted in maximising the stability of the nanosuspension. Witharana et al. [41] studied the aggregation and settling performance of $0.5 \mathrm{wt} \%\left(\mathrm{Al}_{2} \mathrm{O}_{3}\right) / \mathrm{H}_{2} \mathrm{O}$ nanofluid, of $46 \mathrm{~nm}$ particle diameter and water of $\mathrm{pH}$ of 6.3 and 7.8. Their results showed that the samples made of $\mathrm{pH} 6.3$ were stable for more than 30 minutes, and that the nanofluids fabricated with a basefluid of $\mathrm{pH} 7.8$ had a complete settling and particles separation after 30 min. Lee et al. [42] examined the stability and effective thermal conductivity of copper(II) oxide $(\mathrm{CuO})$, of $25 \mathrm{~nm}$ average particles diameter, suspended in deionized water. Measurements of the formed agglomeration particles size, for the nanofluids of $\mathrm{pH} 3$ to 11 , have revealed that the attracted particles were mostly sized between 160 to $280 \mathrm{~nm}$. It was concluded that the stability of the nanofluid was highly influenced by the $\mathrm{pH}$ value and the hydrodynamic size of the embedded particles. In addition, at a $\mathrm{pH}$ value of 11 , the effective thermal conductivity has shown $11 \%$ enhancement over that of the basefluid. Song [43] studied the possibility of stabilising stainless steel (SS) $316 \mathrm{~L} / \mathrm{H}_{2} \mathrm{O}$ nanofluids, of $70 \mathrm{~nm}$ average particles size, with added surfactants of sodium dodecylbenzene sulfonate (SDBS) and sodium dodecyl sulfonate (SDS). In their experiment, the nanofluids investigated were adjusted to a $\mathrm{pH}$ value of $8.0,9.0,10.0,11.0$, and 12.6, before determining their durability and stability. Five approaches were used for their characterisation, namely: 1- absorbance measurement, 2particle size distribution measurement, 3- sedimentation observation, 4- transmission electron microscope (TEM) observation, 5- zeta potential measurement. The long term stability analysis illustrated that the fabricated suspension of $\mathrm{pH} 11$ maintained for 10 days, $\mathrm{pH} 10$ maintained for 3 days, and those of less $\mathrm{pH}$ value have fully settled within one day. On the other hand, the nanofluid of $\mathrm{pH} 12.6$ showed an excess amount of $\mathrm{OH}^{-}$ions, which resulted in disturbing the electrostatic stability, causing the particles to rapidly settle. 
Our review of the available literature quoted above shows that the $\mathrm{pH}$ value of nanofluids has a strong effect on its stability, and that the $\mathrm{pH}$ value of the suspension is influenced by its temperature and NPs concentration. The effect of a fluid $\mathrm{pH}$ was also reported to extend to the level of changing the wettability nature of the surface in contact to it [44, 45]. Given these facts, using an ultrasonic device for preparing nanofluids will lead to an increase in the fluid temperature and hence affect the resulting $\mathrm{pH}$ value of the nanofluid. This rise in temperature is limited by the surrounding atmospheric temperature of the site where the nanofluid is been prepared. This fact needs to be factored in when the commercial production of nanofluids in large scale is considered.

To the best of our knowledge, there is no existing empirical or theoretical relation that links the nanofluid controlled fabrication temperature and concentration to its $\mathrm{pH}$ value. Therefore, in this study, the pH value of SS 316L, copper(I) oxide $\left(\mathrm{Cu}_{2} \mathrm{O}\right)$, and aluminium (Al) NPs dispersed in deionised water (DIW), was measured experimentally at range of controlled sonication bath temperatures and particle concentrations. An empirical correlation was then developed from the measured $\mathrm{pH}$ values, controlled fabrication temperatures, and particle concentrations of the prepared nanofluids and validated to help estimate the $\mathrm{pH}$ value of similar nanofluids robustly, within the same range of conditions. Such correlation is expected to be beneficial to nanofluids manufacturers and even researchers, where it can aid them in predicting the fluids $\mathrm{pH}$ value beforehand, so that a more convenient nanofluid with the desired stability can be achieved.

\section{Experimental procedure}

Materials. Portable pH meter calibration fluids of values 4, 7, and 10 were purchased from Metrohm USA Inc. A purity of 99.9\% Al NPs and SS 316L NPs, of spherical particles shape and particles size between 40 to $60 \mathrm{~nm}$ and 60 to $80 \mathrm{~nm}$, respectively, were purchased from SkySpring Nanomaterials. The chemical composition, as supplied by the manufacture, of the SS 316L NPS is shown in Table 1. A 99.86\% super fine $\mathrm{Cu}_{2} \mathrm{O}$ NPs, of $18 \mathrm{~nm}$ average particles size, were supplied by US Research Nanomaterials. A set of $40 \mathrm{~mL}, 27.5 \mathrm{~mm}$ outer diameter and $95 \mathrm{~mm}$ height, glass clear vials with screwed top were provided by SIGMA-ALDRICH. Deionised water, produced by an Elga PR030BPM1-US Purelab Prima 30 water purification system, was used as the basefluid for the nanofluids preparation after adjusting its $\mathrm{pH}$ value to 7. 
Table 1. Stainless steel 316L chemical composition, wt\% [46].

\begin{tabular}{lccccccccc}
\hline Elements & $\mathrm{Cr}$ & $\mathrm{Ni}$ & $\mathrm{Mo}$ & $\mathrm{Si}$ & $\mathrm{Mn}$ & $\mathrm{S}$ & $\mathrm{C}$ & $\mathrm{P}$ & $\mathrm{Fe}$ \\
\hline $\mathrm{wt} \%$ & $16-18$ & $10-14$ & $2-3$ & $0.75 \max$ & $2 \max$ & $0.03 \max$ & 0.03 max & $0.045 \max$ & balance
\end{tabular}

Characterization. Characterization tests were performed for the $\mathrm{SS} 316 \mathrm{~L}, \mathrm{Al}$, and $\mathrm{Cu}_{2} \mathrm{O}$ NPs through a $9 \mathrm{~kW}$ Rigaku SmartLab, Japan, X-ray diffraction (XRD) analyser and its software, SmartLab Guidance, using a $\mathrm{CuK} \alpha \mathrm{X}$-ray source with a diffraction angle of $2 \theta$ and an incidence beam step of $0.2^{\circ}$ to determine the Bragg's peaks of each element contained in the examined sample. The diffraction scanning angle range was from $20^{\circ}$ to $80^{\circ}$, with a scanning rate of $1 \%$ min. NPs densities were obtained in order to calculate the nanoparticle volumetric concentrations, which was required for the nanofluids fabrication. This was done by first measuring the samples weight, using an ae-ADAM PW 214 analytical balance of $0.0001 \mathrm{~g}$ readability and $\pm 0.0002 \mathrm{~g}$ accuracy, then placing them in a HumiPyc trademark Model 1 gas pycnometer - volumetric analyser at an operational temperature of $25^{\circ} \mathrm{C}$. The $\mathrm{pH}$ values of the DIW and fabricated nanofluids were measured from inside the vials, after placing them on a benchtop, by immersing the Hach PHC20101 Intellical pH measuring electrode connected to a HACH HQ40D portable $\mathrm{pH}$ meter, of accuracy $\pm 0.002 \mathrm{pH}$, vertically to a depth of $5 \mathrm{~cm}$ then obtaining the reading for three times and averaging the values. The aforementioned procedure was done after calibrating the $\mathrm{pH}$ meter, before each conducted measurement and taking into account the temperature compensation, using the three as-received calibration fluids and the manufacturer instructions [47, 48]. Fig. 1 illustrates the experimental setup used for measuring the $\mathrm{pH}$ value of the nanofluid samples, which was also adopted for measuring the DIW $\mathrm{pH}$ value, at different temperature gradient. 


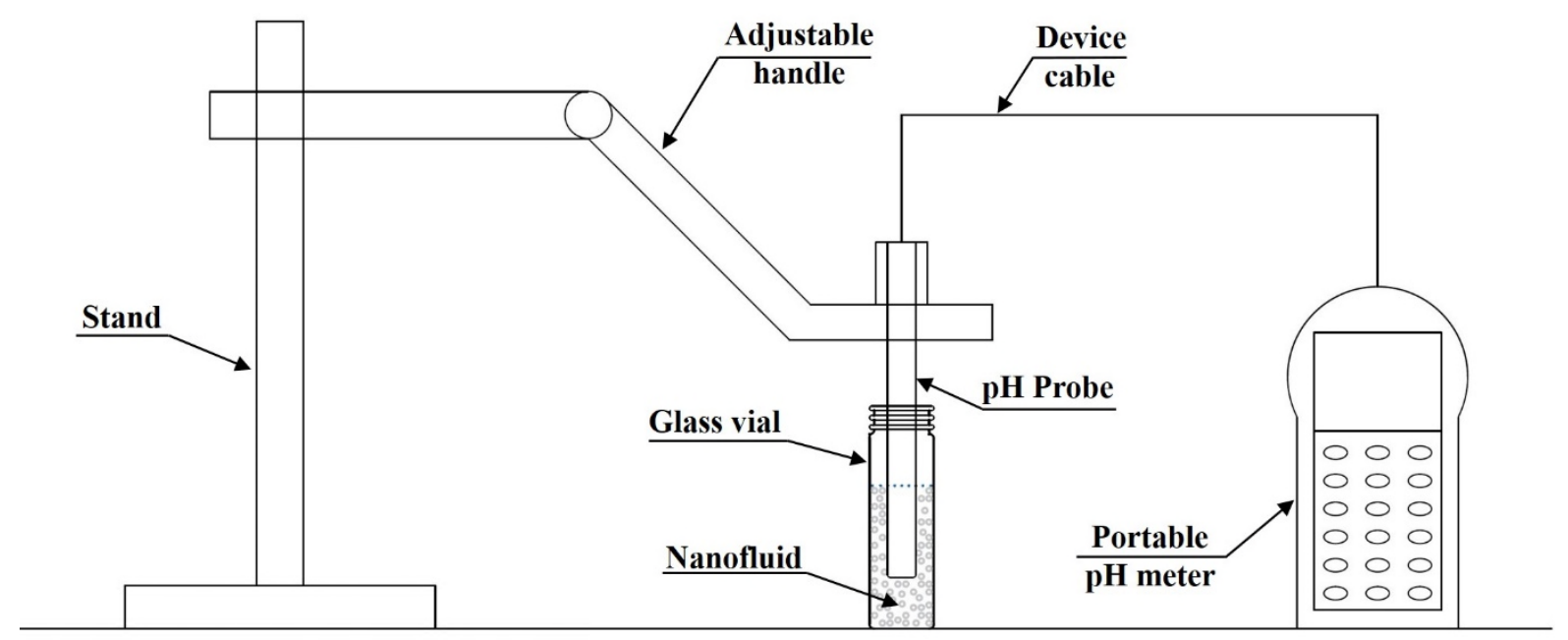

Fig. 1. Experimental setup used in measuring $\mathrm{pH}$ value of nanofluids samples.

Nanofluids preparation. Each nanofluid sample was prepared by placing the NPs first inside the vial then injecting $20 \mathrm{~mL}$ of DIW, using a disposable syringe, on top of the nanopowder after which the vial was sealed using the provided cap. The volume concentrations $(\varphi)$ of NPs used were $0.1,0.3,0.5,0.7$, and $1.0 \mathrm{vol} \%$, for each individual type of material. The vial containing the solution was then placed gently in a Soniclean company benchtop bath type ultrasonic vibrator, running at $100 \%$ power (43 $\mathrm{kHz}$ pulse) and filled with water to the recommended operating level by the manufacturer, for 4 hours to agitate the mixture. This kind of particles dispersion method is known as the two-step approach, which is a common procedure used for the production of nanofluids by many researchers [16, 33]. The sonicator bath temperature was then controlled, at a margin of $\pm 1^{\circ} \mathrm{C}$, for a temperature (T) that ranged from $10^{\circ} \mathrm{C}$ to $60^{\circ} \mathrm{C}$, with an increment of $10^{\circ} \mathrm{C}$, by gradually adding hot or cold water inside the ultrasonic bath and extracting the access water from the device via the attached ejection valve. This was done in order to characterise the variation in nanofluids $\mathrm{pH}\left(\mathrm{pH}_{\mathrm{nf}}\right)$ value at different points of temperature (e.g. $\mathrm{pH}$ value of nanofluid fabricated for 4 hours at fixed sonication bath temperature of $30^{\circ} \mathrm{C}$ with a margin of $\pm 1^{\circ} \mathrm{C}$ ). It should be pointed out that the lab temperature, where the experiments were performed, was $25^{\circ} \mathrm{C}$ and that surfactants or dispersing materials/chemicals were not used for the production of the nanofluids to avoid additional parameters effects on the fluid-particles $\mathrm{pH}$ value. Fig. 2 demonstrates the schematic procedure of the two-step nanofluids preparation. 


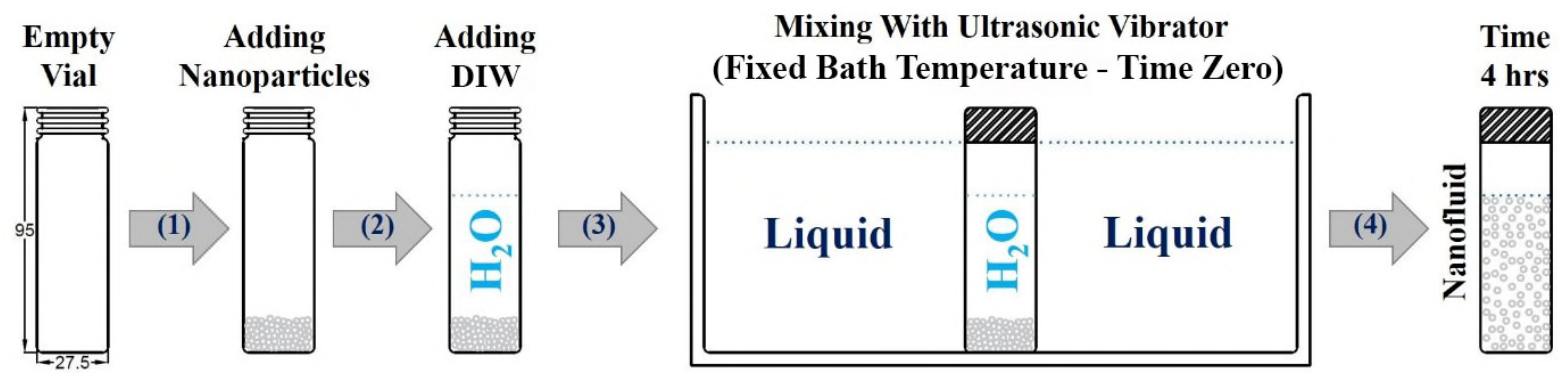

Fig. 2. Schematic procedure for the two-step nanofluids preparation.

Correlations development and validation. The $\mathrm{pH}$ value of the basefluid $\left(\mathrm{pH}_{\mathrm{bf}}\right)$ was first measured for three times and averaged, at a temperature range of $10^{\circ} \mathrm{C}$ to $60^{\circ} \mathrm{C}$ with an increment of $5^{\circ} \mathrm{C}$, as these values reflect the behaviour of the nanofluids with zero nanoparticle concentration. The measurements were then plotted and fitted with a suitable trendline relation in order to obtain the best fit equation, which is valid in the range of $10^{\circ} \mathrm{C} \leq \mathrm{T} \leq 60^{\circ} \mathrm{C}$. Next, the average $\mathrm{pH}$ values of each material employed to form the nanofluids, of $0.1,0.5$, and 1.0 vol\%, were plotted after measuring them at different controlled production temperature, while fixing a single parameter (i.e. sonication bath temperature or particles concentration). The plotted data were then fitted with a trendline relation to acquire their equations and nondimensionalised using a reference temperature $\left(\mathrm{T}_{0}\right)$ and a reference basefluid $\mathrm{pH}$ value $\left(\mathrm{pH}\right.$ bfo), which were selected to be $25^{\circ} \mathrm{C}$ and 7 , respectively. This was done to have the correlations independent of any units using the surrounding temperature condition. Afterwards, the temperature dependant correlation and the particle concentration correlation were combined together and their regression coefficients were taking as unknown variables. An Excel 2016 data analysis tool was used to determine the new correlation regression coefficient variables and the validation of the proposed correlation was performed by comparing it with the 0.3 and 0.7 vol $\%$ as-fabricated nanofluids measured $\mathrm{pH}$ values.

\section{Results and discussion}

X-ray diffraction analysis and nanoparticles density measurement. The XRD pattern of the as-received SS 316L is shown in Fig. 3(a). It can be notice that only ferrite (BCC) and austenite (FCC) peaks are shown in the plot which indicates that the microstructure is solely composed of these two phases. The crystallite sizes obtained from the strongest Bragg's peaks of the austenite (111) and ferrite (110) phases are about $47 \mathrm{~nm}$ and $44 \mathrm{~nm}$, respectively. Figure 
3(b) demonstrates the diffraction pattern of the as-received Al NPs. The peaks observed from the analysis shows some oxidation in the Al sample, practically at angles $2 \theta=20.46^{\circ}, 40.80^{\circ}$, and $48.82^{\circ}$ which are indexed as (020), (041), and (042), subsequently. Crystallite sizes found at the highest peaks of $\mathrm{Al}(111)$ and $\alpha-\mathrm{Al}_{2} \mathrm{O}_{3}(042)$ are about $50 \mathrm{~nm}$ and $91 \mathrm{~nm}$, respectively. Figure 3(c) of the as-received $\mathrm{Cu}_{2} \mathrm{O}$ nanopowder pattern shows the present of $\mathrm{Cu}$ and $\mathrm{CuO}$ peaks, which is normal, since the $\mathrm{Cu}_{2} \mathrm{O}$ NPs are very unstable and when exposed to the outer air the material is likely to oxidize to $\mathrm{CuO}$, or return back to $\mathrm{Cu}$. This kind of behaviour was also stated by the manufacturer [49]. Highest peaks of $\mathrm{Cu}_{2} \mathrm{O}$ (111), $\mathrm{Cu}_{2} \mathrm{O}$ (200), $\mathrm{Cu}_{2} \mathrm{O}$ (220), and $\mathrm{Cu}(111)$ showed crystallite sizes of $20 \mathrm{~nm}, 15 \mathrm{~nm}, 13 \mathrm{~nm}$, and $75 \mathrm{~nm}$, respectively.
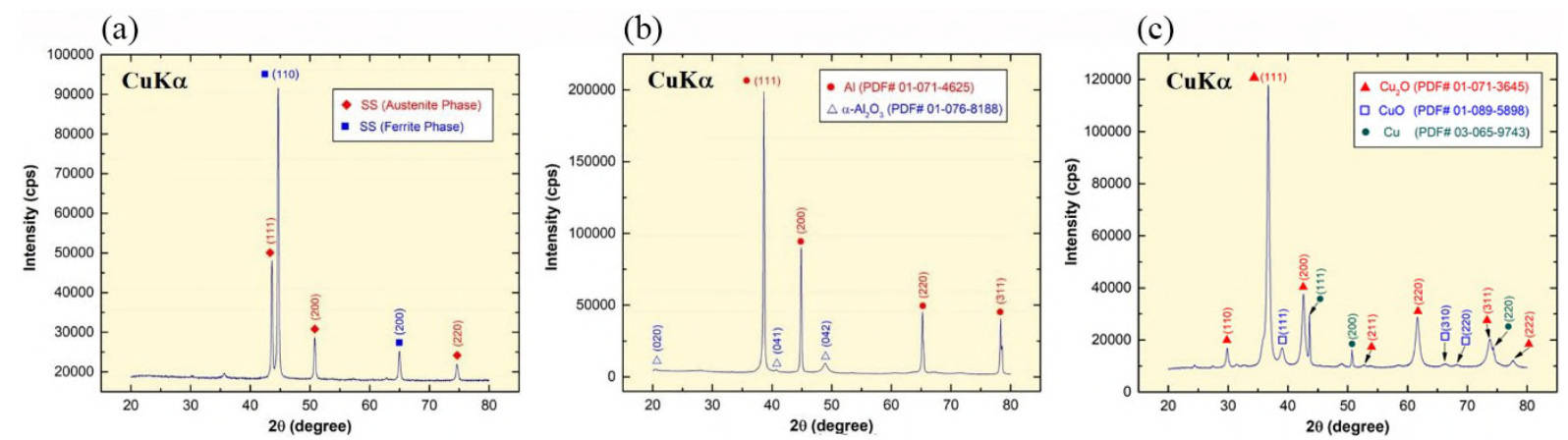

Fig. 3. X-ray diffraction patterns of: (a) Stainless steel 316L NPs, (b) Aluminium NPs, and (c) Copper(I) oxide NPs.

It is worth noting that all crystallite sizes $\left(D_{h k l}\right)$ were obtained using the Scherrer formula (Eq. 1 ), which is commonly used by many researchers [50-53].

$D_{h k l}=\frac{F \lambda}{\beta_{h k l} \cos \theta_{h k l}}$

Where $F$ represents a constant value equal to $0.9, \lambda$ illustrates the wavelength of the $\mathrm{CuK \alpha X}$ ray radiation source and is equal to $0.15405 \mathrm{~nm}, \beta_{h k l}$ demonstrates the full width at half the maximum of the $(h k l)$ diffraction peak, and $\theta_{h k l}$ represents the Bragg angle at $(h k l)$ peak.

Density of the as-received SS $316 \mathrm{~L}, \mathrm{Al}$, and $\mathrm{Cu}_{2} \mathrm{O}$ NPs, based on the volume and mass, are shown in Table 2 along with their standard deviation (SD).

Table 2. The as-received nanoparticles densities.

\begin{tabular}{ccccc}
\hline $\begin{array}{c}\text { Nanoparticle } \\
\text { type }\end{array}$ & $\begin{array}{c}\text { Mass } \\
(\mathrm{g})\end{array}$ & $\begin{array}{c}\text { Sample volume } \\
\left(\mathrm{cm}^{3}\right)\end{array}$ & $\begin{array}{c}\text { Density } \\
\left(\mathrm{g} / \mathrm{cm}^{3}\right)\end{array}$ & $\mathrm{SD} \times 10^{-2}$ \\
\hline
\end{tabular}




\begin{tabular}{ccccc}
\hline Stainless steel 316L & 0.2 & 0.033 & 6.02 & 0.18 \\
Aluminium & 0.2 & 0.621 & 3.22 & 0.81 \\
Copper(I) oxide & 0.2 & 0.566 & 3.53 & 0.14 \\
\hline
\end{tabular}

These density ( $\rho$ ) values were employed in the mixing theory (Eq. 2) [54], which is widely used and agreed upon by many researchers [16], to calculate the amount of NPs required for the preparation of the nanofluids of selected vol\%, where $\mathrm{V}_{\mathrm{np}}, \mathrm{V}_{\mathrm{bf}}$, and $\mathrm{m}$ are the NPs volume, basefluid volume, and mass, respectively.

$v o l \%=\frac{\mathrm{V}_{\mathrm{np}}}{\mathrm{V}_{\mathrm{np}}+\mathrm{V}_{\mathrm{bf}}}=\frac{\left(\frac{m}{\rho}\right)_{n p}}{\left(\frac{m}{\rho}\right)_{n p}+\left(\frac{m}{\rho}\right)_{b f}}$

Basefluid pH variation with temperature. In this study, DIW was used as the basefluid for preparing the different types of nanofluids. Thus, the $\mathrm{pH}$ value of DIW was measured first at a temperature range of $10^{\circ} \mathrm{C}$ to $60^{\circ} \mathrm{C}$, in order to reflect the nanofluids $\mathrm{pH}$ values when the concentration of NPs is equal to zero. Figure 4(a) shows the DIW averaged pH value measurements results at different point of temperature, where a monotonic variation in $\mathrm{pH}$ with temperature is observed. The highest variation in the $\mathrm{pH}$ measurements, within one temperature point, was \pm 0.05 at $10^{\circ} \mathrm{C}$ and $60^{\circ} \mathrm{C}$, and the lowest was \pm 0.02 at $20^{\circ} \mathrm{C}$ to $35^{\circ} \mathrm{C}$. It is important to note that, although the $\mathrm{pH}$ value of DIW, of $\mathrm{pH} 7$ at $25^{\circ} \mathrm{C}$, is increasing/decreasing with the change in liquid temperature, the fluid is still considered to be neutral, but only at that point of temperature. This is because, theoretically, rising/lowering the temperature of DIW above/below $25^{\circ} \mathrm{C}$ would result in increasing/decreasing the amount of free hydrogen ions and hydroxide ions equally, thus the variation seen in $\mathrm{pH}$ value is due to the change in the ionic product constant of water $\left(\mathrm{K}_{\mathrm{w}}\right)$ [55]. A $3^{\text {rd }}$ order polynomial relation fits the data well and the equation obtained from it (Eq. 3 ) is valid in the range of $10^{\circ} \mathrm{C} \leq \mathrm{T} \leq 60^{\circ} \mathrm{C}$.

$p H_{b f}=a_{0}+a_{1} T+a_{2} T^{2}+a_{3} T^{3}$

With $R^{2}=0.993$

Where the regression constants $a_{0}, a_{1}, a_{2}$, and $a_{3}$ are equal to $7.56,-0.027,1.86 \times 10^{-4}$, and $3.22 \times 10^{-7}$, respectively. 


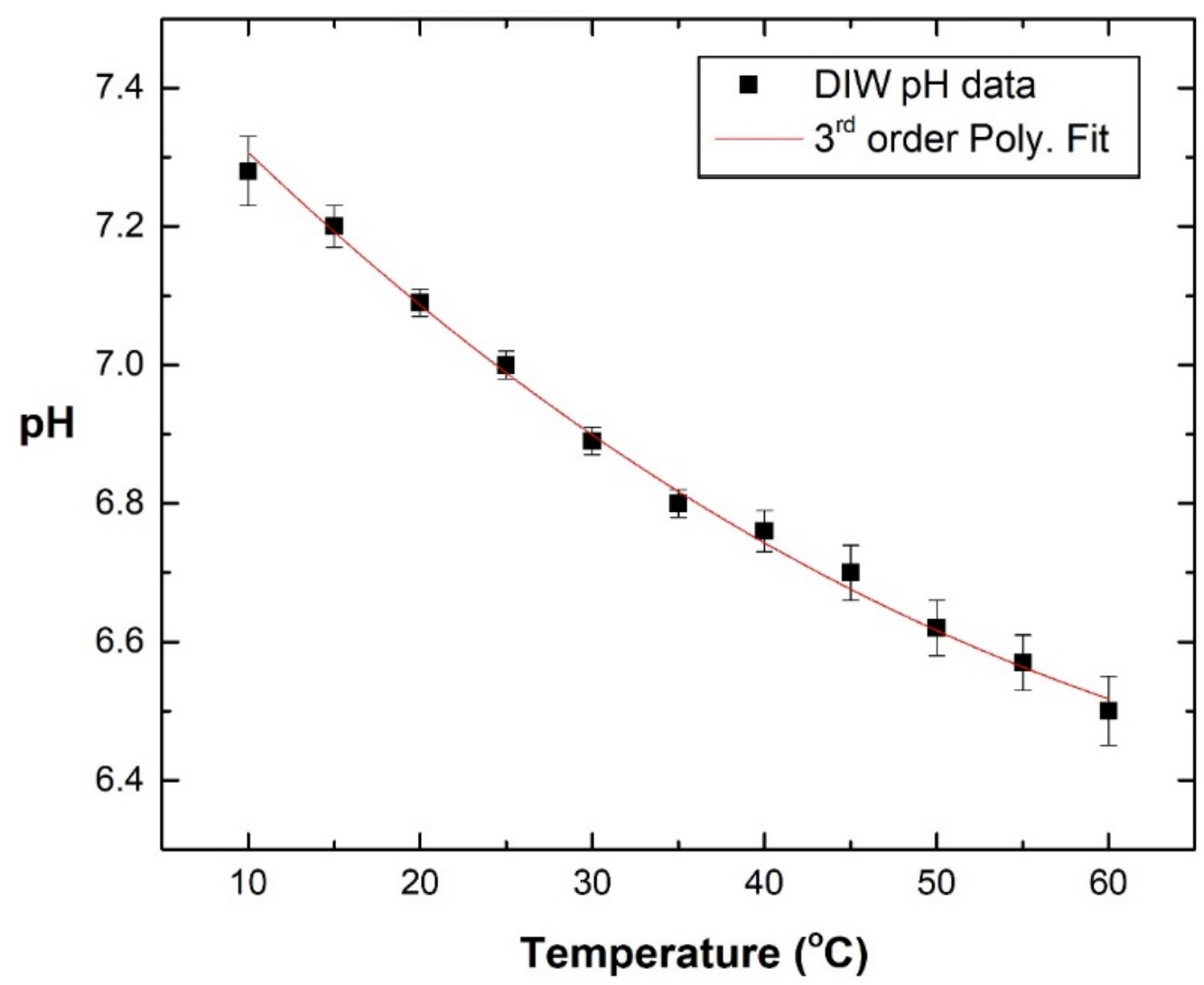

Fig. 4. Measured deionised water $\mathrm{pH}$ value at a temperature range from $10^{\circ} \mathrm{C}$ to $60^{\circ} \mathrm{C}$.

Nanofluids pH variation. The $\mathrm{pH}$ value of $\mathrm{SS} 316 \mathrm{~L} / \mathrm{DIW}, \mathrm{Al}_{2} \mathrm{O}_{3} / \mathrm{DIW}$, and $\mathrm{Cu}_{2} \mathrm{O} / \mathrm{DIW}$ nanofluids for three concentrations, namely, $0.1,0.5$, and $1.0 \mathrm{vol} \%$ is presented in terms of sonication bath temperature variation (Fig. 5(a-c)) and change in NPs volume percentage (Fig. 6(a-c)). The maximum deviation in the three $\mathrm{pH}$ measurements for all three nanofluids, at a single point of temperature, was seen to be \pm 0.04 . Several distinct characteristics of the nanofluids are observed from the plots. Similar to the basefluid behaviour (Fig. 4), the nanofluids $\mathrm{pH}$ value tends to decrease with the increase in fabrication temperature. For example, Fig. 5(a) shows a reduction of $4.40,4.68$, and $7.84 \%$ in the measured $\mathrm{pH}$ values of the 0.1 . 0.5 , and $1.0 \mathrm{vol} \% \mathrm{SS} 316 \mathrm{~L}$ nanofluids at a temperature of $60^{\circ} \mathrm{C}$ compared with their $\mathrm{pH}$ values at $10^{\circ} \mathrm{C}$. In addition, it was further noticed that the increase in NPs concentration caused the fluid $\mathrm{pH}$ value to rise from its initial basefluid state. This kind of outcome is expected, since the added NPs to the basefluid tend to attract the free hydrogen ions within the as-prepared DIW, thus keeping the liquid with higher amount of free hydroxide ions. Hence, the $\mathrm{pH}_{\mathrm{nf}}$ is predicted to be higher than the $\mathrm{pH}_{\mathrm{bf}}$ at each preparation temperature. 

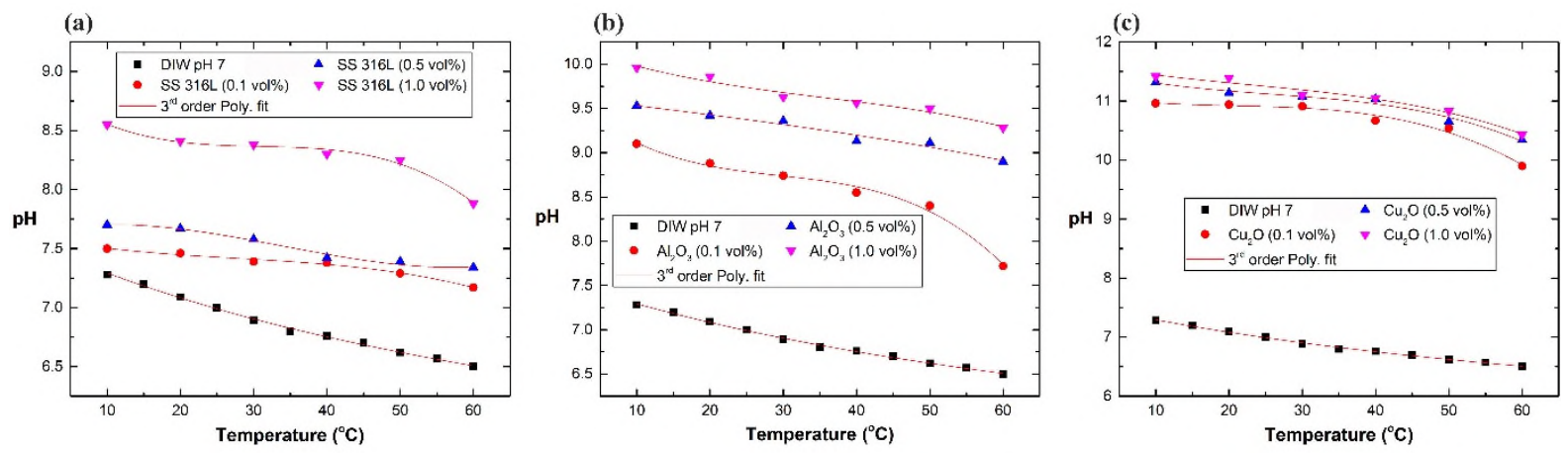

Fig. 5. Nanofluids, of $0.1,0.5$, and $1.0 \mathrm{vol} \%, \mathrm{pH}$ variation with temperature for: (a) SS

$$
\text { 316L/DIW, (b) } \mathrm{Al}_{2} \mathrm{O}_{3} / \mathrm{DIW} \text {, and (c) } \mathrm{Cu}_{2} \mathrm{O} / \mathrm{DIW} \text {. }
$$

Depending on the NPs material used, the nanofluid $\mathrm{pH}$ value can either be strongly influenced by the NPs concentration (e.g. SS $316 \mathrm{~L} / \mathrm{DIW}$ and $\mathrm{Al}_{2} \mathrm{O}_{3} / \mathrm{DIW}$ ), or fixed fabrication temperature (e.g. $\mathrm{Cu}_{2} \mathrm{O} / \mathrm{DIW}$ ). For further illustration, analysing the NPs volumetric concentration and controlled production temperature effect on the $\mathrm{pH}$ value of $\mathrm{Al}_{2} \mathrm{O}_{3} / \mathrm{DIW}$ nanofluids (Fig. 5(b) and $6(\mathrm{~b}))$ showed that the average change in $\mathrm{pH}$ obtained from increasing the concentration alone across the examined temperature range was $11.13 \%$, while increasing the production temperature for each fixed concentration had an average $\mathrm{pH}$ variation of $9.53 \%$.
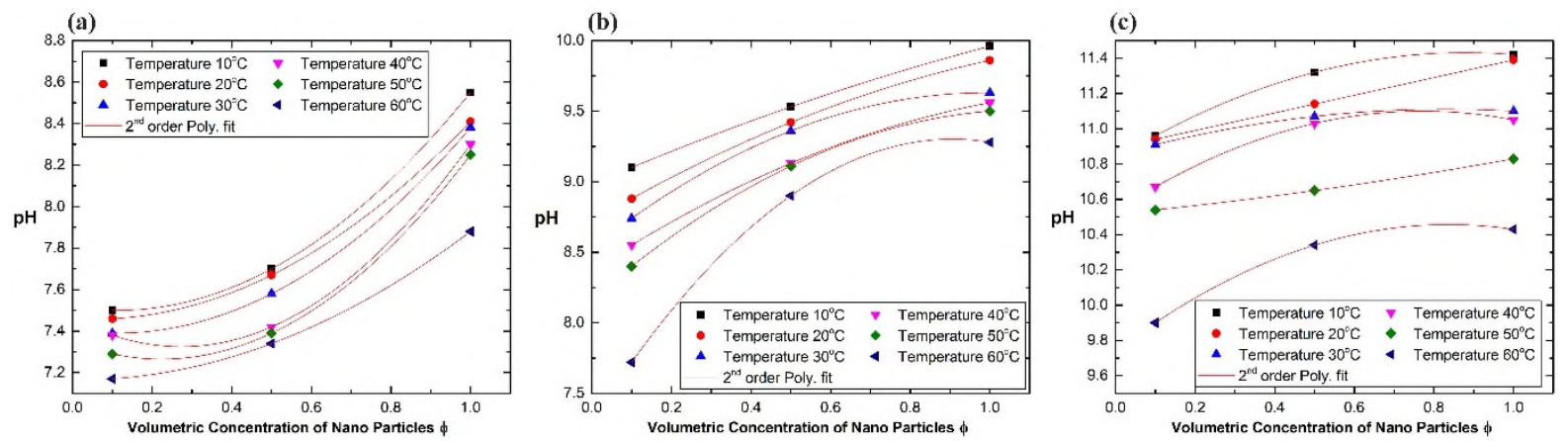

Fig. 6. Nanofluids, of $0.1,0.5$, and $1.0 \mathrm{vol} \%$, $\mathrm{pH}$ variation with concentration for: (a) SS 316L/DIW, (b) $\mathrm{Al}_{2} \mathrm{O}_{3} / \mathrm{DIW}$, and (c) $\mathrm{Cu}_{2} \mathrm{O} / \mathrm{DIW}$.

In addition, it can be seen that all three types of nanofluids $\mathrm{pH}$ data, at a specific concentration, follows a $3^{\text {rd }}$ order polynomial relation fit which can be expressed by Eq. 4 along with the regression constants shown in Table 3.

$p H_{n f}=b_{0}+b_{1} \mathrm{~T}+b_{2} T^{2}+b_{3} T^{3}$ 
Furthermore, from the data in Fig. 6, at each as-prepared fluid fabrication temperature, the variation in $\mathrm{pH}$ value in respect of NPs volume percentage is seen to cohabit a $2^{\text {nd }}$ order polynomial relation, for all three types of nanofluids, which can be expressed as:

$p H_{n f}=c_{0}+c_{1} \phi+c_{2} \phi^{2}$

With $\mathrm{R}^{2}=1$

Equations 4 and 5 are valid in the range of $10^{\circ} \mathrm{C} \leq \mathrm{T} \leq 60^{\circ} \mathrm{C}$, and 0.1 vol $\% \leq \varphi \leq 1.0$ vol\% with the regression constants of Eq. 5 (i.e. $c_{0}, c_{1}$, and $c_{2}$ ) are tabulated in Table 4. 
Table 3. Regression coefficients of Eq. 4 for SS 316L, $\mathrm{Al}_{2} \mathrm{O}_{3} / \mathrm{DIW}$, and $\mathrm{Cu}_{2} \mathrm{O} / \mathrm{DIW}$ nanofluids.

\begin{tabular}{|c|c|c|c|c|c|c|c|c|c|}
\hline \multirow{2}{*}{$\begin{array}{l}\text { Regression } \\
\text { constants }\end{array}$} & \multicolumn{3}{|c|}{ SS 316L/DIW } & \multicolumn{3}{|c|}{$\mathrm{Al}_{2} \mathrm{O}_{3} / \mathrm{DIW}$} & \multicolumn{3}{|c|}{$\mathrm{Cu}_{2} \mathrm{O} / \mathrm{DIW}$} \\
\hline & $0.1 \mathrm{vol} \%$ & $0.5 \mathrm{vol} \%$ & $1.0 \mathrm{vol} \%$ & $0.1 \mathrm{vol} \%$ & $0.5 \mathrm{vol} \%$ & $1.0 \mathrm{vol} \%$ & $0.1 \mathrm{vol} \%$ & $0.5 \mathrm{vol} \%$ & $1.0 \mathrm{vol} \%$ \\
\hline$b_{0}$ & 7.60 & 7.63 & 8.93 & 9.68 & 9.63 & 10.24 & 11.10 & 11.56 & 11.64 \\
\hline$b_{1}$ & -0.013 & 0.014 & -0.052 & -0.077 & -0.01 & -0.032 & -0.021 & -0.033 & -0.024 \\
\hline$b_{2}$ & $3.226 \times 10^{-4}$ & $-7.528 \times 10^{-4}$ & $1.64 \times 10^{-3}$ & 0.0023 & $-2.381 \times 10^{-6}$ & $5.976 \times 10^{-4}$ & $8.722 \times 10^{-4}$ & $9.361 \times 10^{-4}$ & $5.266 \times 10^{-4}$ \\
\hline$b_{3}$ & $-3.889 \times 10^{-6}$ & $7.407 \times 10^{-6}$ & $-1.769 \times 10^{-5}$ & $-2.574 \times 10^{-5}$ & $-5.556 \times 10^{-7}$ & $-5.556 \times 10^{-6}$ & $-1.426 \times 10^{-5}$ & $-1.213 \times 10^{-5}$ & $-7.685 \times 10^{-6}$ \\
\hline$R^{2}$ & 0.974 & 0.959 & 0.970 & 0.978 & 0.921 & 0.932 & 0.955 & 0.950 & 0.941 \\
\hline
\end{tabular}


Table 4. Regression coefficients of Eq. 5 for SS 316L, $\mathrm{Al}_{2} \mathrm{O}_{3} / \mathrm{DIW}$, and $\mathrm{Cu}_{2} \mathrm{O} / \mathrm{DIW}$ nanofluids.

\begin{tabular}{|c|c|c|c|c|c|c|c|c|c|}
\hline \multirow{2}{*}{$\begin{array}{l}\text { Temperature } \\
\left({ }^{\circ} \mathrm{C}\right)\end{array}$} & \multicolumn{3}{|c|}{ SS 316L/DIW } & \multicolumn{3}{|c|}{$\mathrm{Al}_{2} \mathrm{O}_{3} / \mathrm{DIW}$} & \multicolumn{3}{|c|}{$\mathrm{Cu}_{2} \mathrm{O} / \mathrm{DIW}$} \\
\hline & $c_{0}$ & $c_{1}$ & $c_{2}$ & $c_{0}$ & $c_{1}$ & $c_{2}$ & $c_{0}$ & $c_{1}$ & $c_{2}$ \\
\hline 10 & 7.52 & -0.300 & 1.333 & 8.98 & 1.218 & -0.239 & 10.83 & 1.367 & -0.778 \\
\hline 20 & 7.46 & -0.112 & 1.061 & 8.72 & 1.663 & -0.522 & 10.89 & 0.5 & $4.428 \times 10^{-15}$ \\
\hline 30 & 7.40 & -0.275 & 1.250 & 8.53 & 2.223 & -1.122 & 10.85 & 0.627 & -0.378 \\
\hline 40 & 7.46 & -1.007 & 1.844 & 8.37 & 1.843 & -0.656 & 10.53 & 1.473 & -0.956 \\
\hline 50 & 7.35 & -0.730 & 1.633 & 8.17 & 2.438 & -1.106 & 10.52 & 0.218 & 0.094 \\
\hline 60 & 7.16 & -0.012 & 0.728 & 7.30 & 4.410 & -2.433 & 9.74 & 1.713 & -1.022 \\
\hline
\end{tabular}


Correlation development. From analysing the experimental results of Fig. 5 and Fig. 6, it was found that the $\mathrm{pH}$ value of each type of nanofluid examined depends on the volumetric concentration of the NPs used and the temperature of suspension fabrication. In order to establish a joint link between the two parameters (i.e. $\mathrm{T}$ and $\phi$ ) and the nanofluid $\mathrm{pH}$ value, an analysis of the variation of these parameters independently was carried out. Having the correlation independent of any units, the $\mathrm{pH}_{\mathrm{nf}}$ was nondimensionalised by that of the basefluid, at room temperature conditions, using the parameters $\mathrm{pH}_{\mathrm{bf0}}$ and $\mathrm{T}_{0}$ values.

Influence of temperature. The $\mathrm{pH}$ values of $\mathrm{SS} 316 \mathrm{~L} / \mathrm{DIW}, \mathrm{Al}_{2} \mathrm{O}_{3} / \mathrm{DIW}$, and $\mathrm{Cu}_{2} \mathrm{O} / \mathrm{DIW}$ nanofluids in Fig. 5 were nondimensionalised using the value of $\mathrm{pH}_{\mathrm{bf} 0}$ then plotted in contrast to the nondimensionalised temperature $\left(\frac{T}{T_{0}}\right)$, for each of the three nanoparticle concentrations. It can be observed from Fig. 7 that the $\mathrm{pH}$ ratio $\left(\frac{p H_{n f}}{p H_{b f 0}}\right)$ against $\left(\frac{T}{T_{0}}\right)$ corresponds to a $3^{\text {rd }}$ order polynomial relation. Thus, the correlation for $\left(\frac{p H_{n f}}{p H_{b f 0}}\right)$ as a function of $\left(\frac{T}{T_{0}}\right)$ can be best represented as:

$\frac{p H_{n f}}{p H_{b f 0}}=d_{0}+d_{1}\left(\frac{T}{T_{0}}\right)+d_{2}\left(\frac{T}{T_{0}}\right)^{2}+d_{3}\left(\frac{T}{T_{0}}\right)^{3}$
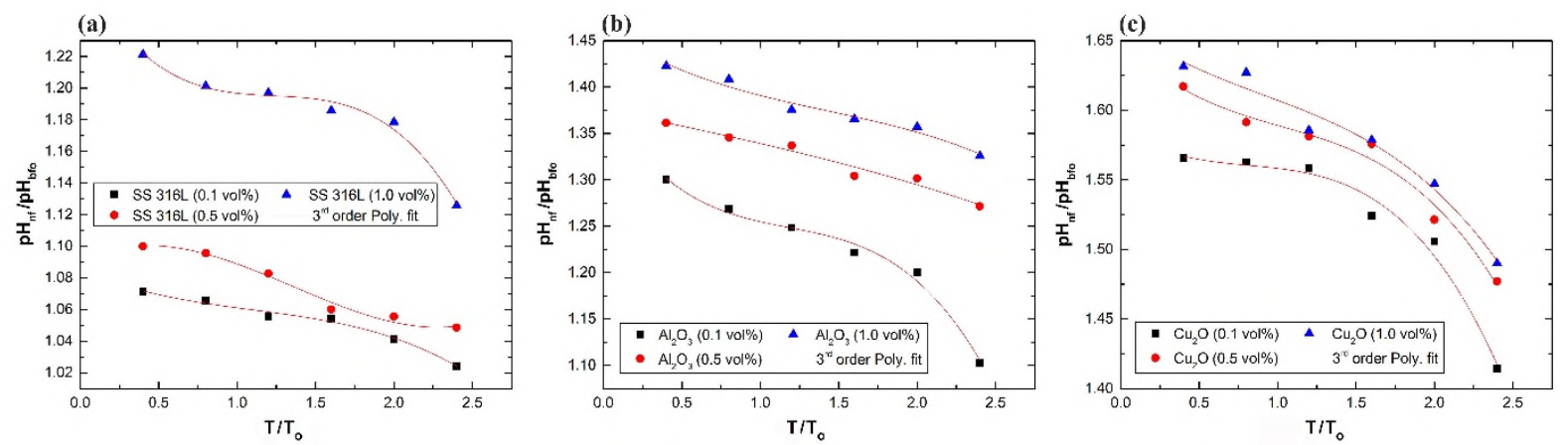

Fig. 7. Nanofluids, of $0.1,0.5$, and $1.0 \mathrm{vol} \%$, nondimensionalised $\mathrm{pH}$ variation against $\left(\frac{T}{T_{0}}\right)$ for: (a) SS 316L/DIW, (b) $\mathrm{Al}_{2} \mathrm{O}_{3} / \mathrm{DIW}$, and (c) $\mathrm{Cu}_{2} \mathrm{O} / \mathrm{DIW}$.

Influence of concentration. From Fig. 6 and Eq. 5, it was demonstrated that the variation in $p H_{n f}$ as a function of $\phi$ followed a $2^{\text {nd }}$ order polynomial relation at a fixed fabrication temperature. This was examined for all three types of nanofluids that were produced from a controlled sonication bath temperature that ranged from $10^{\circ} \mathrm{C}$ to $60^{\circ} \mathrm{C}$. Due to the nature of Eq. 5 , the appropriate nondimensionalisation representation of the correlation can be shown as following: 
$\frac{p H_{n f}}{p H_{b f 0}}=e_{0}+e_{1} \phi+e_{2} \phi^{2}$

Proposed correlation. From the previous two analysis of the influence of each parameter, it was found that a general $p H_{n f}$ correlation can be illustrated by combining Eq. 6 and Eq. 7 in the following format:

$\frac{p H_{n f}}{p H_{b f 0}}=\left[d_{o}+d_{1}\left(\frac{T}{T_{0}}\right)+d_{2}\left(\frac{T}{T_{0}}\right)^{2}+d_{3}\left(\frac{T}{T_{0}}\right)^{3}\right] \cdot\left[e_{0}+e_{1} \phi+e_{2} \phi^{2}\right]$

Equation 8 was then extended to Eq. 9 because of the infinite number of solutions that can be obtained at the current state to the regression coefficients.

$\frac{p H_{n f}}{p H_{b f 0}}=X_{0}+X_{1}\left(\frac{T}{T_{0}}\right)+X_{2}\left(\frac{T}{T_{0}}\right)^{2}+X_{3}\left(\frac{T}{T_{0}}\right)^{3}+X_{4} \phi+X_{5} \phi\left(\frac{T}{T_{0}}\right)+X_{6} \phi\left(\frac{T}{T_{0}}\right)^{2}+$

$X_{7} \phi\left(\frac{T}{T_{0}}\right)^{3}+X_{8} \phi^{2}+X_{9} \phi^{2}\left(\frac{T}{T_{0}}\right)+X_{10} \phi^{2}\left(\frac{T}{T_{0}}\right)^{2}+X_{11} \phi^{2}\left(\frac{T}{T_{0}}\right)^{3}$

Where the correspondence of the new regression coefficients (i.e. $X_{0}$ to $X_{11}$ ) are shown in Table 5 .

Table 5. Regression coefficients of Eq. 9 and their correspondence.

\begin{tabular}{cccccc}
\hline $\begin{array}{c}\text { Regression } \\
\text { coefficient }\end{array}$ & Representation & $\begin{array}{r}\text { Regression } \\
\text { coefficient }\end{array}$ & Representation & $\begin{array}{r}\text { Regression } \\
\text { coefficient }\end{array}$ & Representation \\
\hline$X_{0}$ & $d_{0} \cdot e_{0}$ & $X_{4}$ & $d_{o} \cdot e_{1}$ & $X_{8}$ & $d_{o} \cdot e_{2}$ \\
$X_{1}$ & $d_{1} \cdot e_{0}$ & $X_{5}$ & $d_{1} \cdot e_{1}$ & $X_{9}$ & $d_{1} \cdot e_{2}$ \\
$X_{2}$ & $d_{2} \cdot e_{0}$ & $X_{6}$ & $d_{2} \cdot e_{1}$ & $X_{10}$ & $d_{2} \cdot e_{2}$ \\
$X_{3}$ & $d_{3} \cdot e_{0}$ & $X_{7}$ & $d_{3} \cdot e_{1}$ & $X_{11}$ & $d_{3} \cdot e_{2}$ \\
\hline
\end{tabular}

The Excel 2016 data analysis regression tool was then used to determine the values of the unknown regression coefficients of Eq. 9 for the different types of nanofluids from their nondimensionalised $\mathrm{pH}_{\mathrm{nf}}$ measured data and $\left(\frac{T}{T_{0}}\right)$. Table 6 shows the statistical analysis tabulation of the regression coefficients, where Eq. 9 with the coefficients of Table 6 has a range of validity of $10^{\circ} \mathrm{C} \leq \mathrm{T} \leq 60^{\circ} \mathrm{C}$, and $0.1 \mathrm{vol} \% \leq \varphi \leq 1.0 \mathrm{vol} \%$. 
Table 6. Regression coefficients of Eq. 9 values for different as-fabricated nanofluids.

\begin{tabular}{|c|c|c|c|}
\hline $\begin{array}{c}\text { Regression } \\
\text { constant }\end{array}$ & SS 316L/DIW & $\mathrm{Al}_{2} \mathrm{O}_{3} / \mathrm{DIW}$ & $\mathrm{Cu}_{2} \mathrm{O} / \mathrm{DIW}$ \\
\hline$X_{0}$ & 1.104 & 1.395 & 1.562 \\
\hline$X_{1}$ & -0.107 & -0.376 & -0.053 \\
\hline$X_{2}$ & 0.090 & 0.289 & 0.072 \\
\hline$X_{3}$ & -0.025 & -0.081 & -0.033 \\
\hline$X_{4}$ & -0.227 & -0.144 & 0.255 \\
\hline$X_{5}$ & 0.703 & 1.099 & -0.229 \\
\hline$X_{6}$ & -0.685 & -0.922 & 0.073 \\
\hline$X_{7}$ & 0.180 & 0.249 & 0.007 \\
\hline$X_{8}$ & 0.397 & 0.212 & -0.154 \\
\hline$X_{9}$ & -0.781 & -0.837 & 0.197 \\
\hline$X_{10}$ & 0.741 & 0.686 & -0.097 \\
\hline$X_{11}$ & -0.195 & -0.181 & 0.009 \\
\hline$R^{2}$ & 0.995 & 0.985 & 0.953 \\
\hline Maximum deviation & $-0.90 \%$ & $-1.24 \%$ & $+0.95 \%$ \\
\hline Average deviation & $0.28 \%$ & $0.50 \%$ & $0.38 \%$ \\
\hline
\end{tabular}

Validation of the new correlation. In order to validate the newly developed correlation, the $\mathrm{pH}$ of the as-prepared 0.3 and 0.7 vol\% nanofluids of different fixed fabrication temperatures were compared with the proposed correlation in terms of experimental measurement against 
theoretical computation as demonstrated in Fig. 8. The central line in Fig. 8(a-b) represents a perfect match between the new correlation values and the experimental data. It can be notice that there exists some level of deviation between the measured data and the correlation prediction, especially with the measured data of SS 316L/DIW nanofluid. Nevertheless, the correlation shows very good estimation towards the $p H_{n f}$ for all three types of nanofluids, where the highest prediction error was shown to be $-8.09 \%$ (at $\mathrm{T}=40^{\circ} \mathrm{C}$ and $\varphi=0.7 \mathrm{vol} \%$ ) for SS 316L/DIW, $+5.08 \%$ (at $\mathrm{T}=60^{\circ} \mathrm{C}$ and $\varphi=0.7 \mathrm{vol} \%$ ) for $\mathrm{Al}_{2} \mathrm{O}_{3} / \mathrm{DIW}$, and $+2.31 \%$ (at $\mathrm{T}=$ $60^{\circ} \mathrm{C}$ and $\varphi=0.7 \mathrm{vol} \%$ ) for $\mathrm{Cu}_{2} \mathrm{O} / \mathrm{DIW}$. The average error of the newly proposed correlation, for the 0.1-1.0 vol\% SS 316L/DIW, $\mathrm{Al}_{2} \mathrm{O}_{3} / \mathrm{DIW}$, and $\mathrm{Cu}_{2} \mathrm{O} / \mathrm{DIW}$ samples, was found to be $2.18 \%, 0.92 \%$, and $0.63 \%$, respectively. Given a specific controlled sonication bath temperature and NPs concentration, the correlation of Eq. 9 insures at least $91 \%$ confidence that the value will be between the upper and lower prediction error limits of the curve-fit range. Such level of error is acceptable for many industrial applications, since the highest deviation from the actual $\mathrm{pH}_{\mathrm{nf}}$ measurement would be within a value of \pm 0.57 (i.e. less than 1).
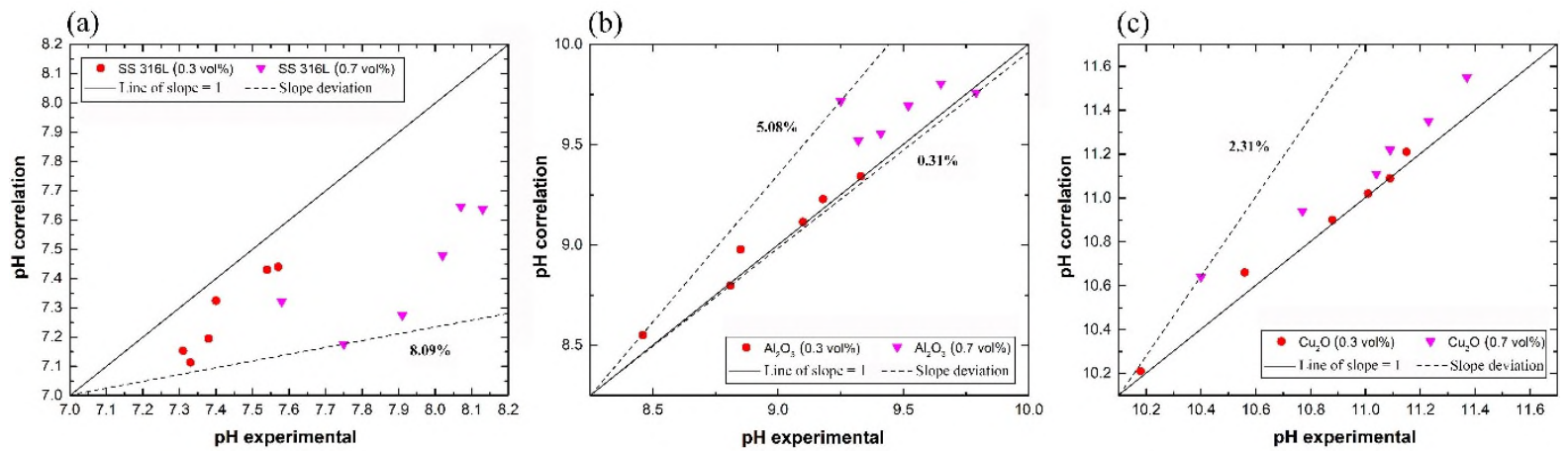

Fig. 8. Comparison between the new correlation prediction (Eq. 9) and the measured pH of: (a) $\mathrm{SS} 316 \mathrm{~L} / \mathrm{DIW}$, (b) $\mathrm{Al}_{2} \mathrm{O}_{3} / \mathrm{DIW}$, and (c) $\mathrm{Cu}_{2} \mathrm{O} / \mathrm{DIW}$.

\section{Summary}

Measurements of the $\mathrm{pH}$ value of three types of nanofluids, namely, SS 316L/DIW, $\mathrm{Al}_{2} \mathrm{O}_{3} / \mathrm{DIW}$, and $\mathrm{Cu}_{2} \mathrm{O} / \mathrm{DIW}$ were performed in order to develop a general correlation that can predict the $\mathrm{pH}_{\mathrm{nf}}$ value, within the conducted experiments range, from the liquid production temperature and nanoparticle volumetric concentration. All three types of nanofluids were fabricated using a controlled sonication bath temperature two-step approach, with 0.1 to 1.0 vol\% of NPs. The following conclusions are drawn: 
- The experimental findings have indicated that, increasing the NPs concentration in the basefluid had an alkaline effect, while rising the temperature caused the nanofluid to be more acidic. Such behaviours are expected to be a result of: 1- the NPs attraction of free hydrogen ions within the basefluid, and 2- the increase in the amount of ions been freed from their water molecules caused by the rise in fluid temperature.

- In addition, depending on the nanoparticle material, the $p H_{n f}$ can be strongly influenced by either the controlled sonication bath temperature, as in the case of $\mathrm{Cu}_{2} \mathrm{O} / \mathrm{DIW}$, or the changes in nanofluid particle concentration (e.g. SS 316L/DIW, and $\mathrm{Al}_{2} \mathrm{O}_{3} / \mathrm{DIW}$ ). For instant, by analysing the $\mathrm{pH}$ value of $\mathrm{Al}_{2} \mathrm{O}_{3} / \mathrm{DIW}$ for the two aforementioned parameters, the average change in $\mathrm{pH}_{\mathrm{nf}}$ due to increasing the particles volumetric concentration alone over the fixed bath temperatures have shown to be $11.13 \%$, whereas varying the processing controlled temperatures for each volumetric concentration has resulted in a $9.53 \%$ average change in $\mathrm{pH}$.

- Using the experimental data, a new $\mathrm{pH}_{\mathrm{nf}}$ correlation was developed as a function of fabrication bath temperature and NPs volume concentration to estimate the $\mathrm{pH}$ value of the three previous types of nanofluids. The proposed correlation has illustrated a high prediction capability, where its average error for SS 316L/DIW, $\mathrm{Al}_{2} \mathrm{O}_{3} / \mathrm{DIW}$, and $\mathrm{Cu}_{2} \mathrm{O} / \mathrm{DIW}$ have shown to be $2.18 \%, 0.92 \%$, and $0.63 \%$, respectively.

Nevertheless, it should be acknowledged that, due to the variation in nanofluid dispersant methods and their NPs crystal structures, the presented correlation are very helpful and reliable for applications that uses nanofluids fabricated similarly to the conducted study approach and parametric range. These correlations will be advanced for additional parameters such as NPs average size, shape, and the existence of surfactants.

\section{Acknowledgements}

The authors of this manuscript wish to acknowledge the help and support provided by their institutes for conducting this research work.

\section{References}

[1] S.U.S. Choi, J.A. Eastman, Enhancing thermal conductivity of fluids with nanoparticles, ; Argonne National Lab., IL (United States), 1995.

[2] P. Keblinski, J.A. Eastman, D.G. Cahill, Nanofluids for thermal transport, Materials Today, 8 (2005) 36-44. 
[3] C. Anushree, J. Philip, Assessment of long term stability of aqueous nanofluids using different experimental techniques, Journal of Molecular Liquids, 222 (2016) 350-358.

[4] S.U. Ilyas, R. Pendyala, A.S. Shuib, N. Marneni, A review on the viscous and thermal transport properties of nanofluids, in: International Conference on Process Engineering and Advanced Materials, ICPEAM 2012, Trans Tech Publications Ltd, Kuala Lumpur, 2014, pp. $18-27$.

[5] R. Shanthi, S.S. Anandan, V. Ramalingam, HEAT TRANSFER ENHANCEMENT USING NANOFLUIDS An Overview, Therm. Sci., 16 (2012) 423-444.

[6] D.S. Wen, G.P. Lin, S. Vafaei, K. Zhang, Review of nanofluids for heat transfer applications, Particuology, 7 (2009) 141-150.

[7] L. Vekas, D. Bica, M.V. Avdeev, Magnetic nanoparticles and concentrated magnetic nanofluids: Synthesis, properties and some applications, China Particuology, 5 (2007) 43-49.

[8] K.S. Reddy, N.R. Kamnapure, S. Srivastava, Nanofluid and nanocomposite applications in solar energy conversion systems for performance enhancement: a review, Int. J. Low Carbon Technol., 12 (2017) 1-23.

[9] M. Sheikholeslami, D.D. Ganji, Chapter 1 - Application of Nanofluids, in: M. Sheikholeslami, D.D. Ganji (Eds.) Applications of Semi Analytical Methods for Nanofluid Flow and Heat Transfer, Elsevier, 2018, pp. 1-44.

[10] D. Mansoury, I.D. Faramarz, A. Kiani, A.J. Chamkha, M. Sharifpur, Heat transfer and flow characteristics of A12O3/water nanofluid in various heat exchangers: Experiments on counter flow, Heat Transfer Eng, (2018) 1-36.

[11] A.J. Chamkha, M. Molana, A. Rahnama, F. Ghadami, On the nanofluids applications in microchannels: A comprehensive review, Powder Technol., 332 (2018) 287-322.

[12] S.U. Ilyas, R. Pendyala, N. Marneni, Stability and Agglomeration of Alumina Nanoparticles in Ethanol-Water Mixtures, in: M.A. Bustam, L.K. Keong, Z. Man, A.A. Hassankiadeh, Y.Y. Fong (Eds.) 4th International Conference on Process Engineering and Advanced Materials, ICPEAM 2016, Elsevier Ltd, 2016, pp. 290-297.

[13] S.U. Ilyas, R. Pendyala, N. Marneni, Preparation, Sedimentation, and Agglomeration of Nanofluids, Chemical Engineering \& Technology, 37 (2014) 2011-2021.

[14] S. Mukherjee, P.C. Mishra, P. Chaudhuri, Stability of Heat Transfer Nanofluids - A Review, ChemBioEng Reviews, 5 (2018) 312-333.

[15] M.K. Bushehri, A. Mohebbi, H.H. Rafsanjani, Prediction of Thermal Conductivity and Viscosity of Nanofluids by Molecular Dynamics Simulation, J. Eng. Thermophys., 25 (2016) 389-400.

[16] N. Ali, J.A. Teixeira, A. Addali, A Review on Nanofluids: Fabrication, Stability, and Thermophysical Properties, J. Nanomater., 2018 (2018) 33. 
[17] J. Hong, D. Kim, Effects of aggregation on the thermal conductivity of alumina/water nanofluids, Thermochim Acta, 542 (2012) 28-32.

[18] O. Arthur, M.A. Karim, An investigation into the thermophysical and rheological properties of nanofluids for solar thermal applications, Renewable \& Sustainable Energy Reviews, 55 (2016) 739-755.

[19] K.S. Suganthi, K.S. Rajan, Metal oxide nanofluids: Review of formulation, thermophysical properties, mechanisms, and heat transfer performance, Renewable \& Sustainable Energy Reviews, 76 (2017) 226-255.

[20] I.M. Mahbubul, E.B. Elcioglu, R. Saidur, M.A. Amalina, Optimization of ultrasonication period for better dispersion and stability of TiO2-water nanofluid, Ultrason Sonochem, 37 (2017) 360-367.

[21] P.K. Das, A review based on the effect and mechanism of thermal conductivity of normal nanofluids and hybrid nanofluids, Journal of Molecular Liquids, 240 (2017) 420-446.

[22] X.F. Peng, X.L. Yu, L.F. Xia, X. Zhong, Influence factors on suspension stability of nanofluids, Zhejiang Daxue Xuebao (Gongxue Ban), 41 (2007) 577-580.

[23] R. Choudhary, D. Khurana, A. Kumar, S. Subudhi, Stability analysis of Al2O3/water nanofluids, J. Exp. Nanosci., 12 (2017) 140-151.

[24] H. Zhu, C. Zhang, Y. Tang, J. Wang, B. Ren, Y. Yin, Preparation and thermal conductivity of suspensions of graphite nanoparticles, 2007.

[25] X. Li, D. Zhu, X. Wang, Evaluation on dispersion behavior of the aqueous copper nanosuspensions, J Colloid Interface Sci, 310 (2007) 456-463.

[26] E.B. Haghighi, N. Nikkam, M. Saleemi, M. Behi, S.A. Mirmohammadi, H. Poth, R. Khodabandeh, M.S. Toprak, M. Muhammed, B. Palm, Shelf stability of nanofluids and its effect on thermal conductivity and viscosity, Meas. Sci. Technol., 24 (2013).

[27] S. Askari, H. Koolivand, M. Pourkhalil, R. Lotfi, A. Rashidi, Investigation of Fe3O4/Graphene nanohybrid heat transfer properties: Experimental approach, Int. Commun. Heat Mass Transf., 87 (2017) 30-39.

[28] M. Mohammadi, M. Dadvar, B. Dabir, TiO2/SiO2 nanofluids as novel inhibitors for the stability of asphaltene particles in crude oil: Mechanistic understanding, screening, modeling, and optimization, Journal of Molecular Liquids, 238 (2017) 326-340.

[29] K.Y. Leong, Z.A. Najwa, K.Z.K. Ahmad, H.C. Ong, Investigation on Stability and Optical Properties of Titanium Dioxide and Aluminum Oxide Water-Based Nanofluids, Int J Thermophys, 38 (2017).

[30] P.C.M. Kumar, M. Muruganandam, Stability Analysis of Heat Transfer MWCNT with Different Base Fluids, J. Appl. Fluid Mech., 10 (2017) 51-59. 
[31] A. Menbari, A.A. Alemrajabi, Y. Ghayeb, Investigation on the stability, viscosity and extinction coefficient of CuO-A12O3/Water binary mixture nanofluid, Exp. Therm. Fluid Sci., 74 (2016) 122-129.

[32] Y. Hwang, J.K. Lee, J.K. Lee, Y.M. Jeong, S.I. Cheong, Y.C. Ahn, S.H. Kim, Production and dispersion stability of nanoparticles in nanofluids, Powder Technol., 186 (2008) 145-153.

[33] W. Yu, H.Q. Xie, A Review on Nanofluids: Preparation, Stability Mechanisms, and Applications, J. Nanomater., 2012 (2012).

[34] X.J. Wang, D.S. Zhu, S. Yang, Investigation of $\mathrm{pH}$ and SDBS on enhancement of thermal conductivity in nanofluids, Chem. Phys. Lett., 470 (2009) 107-111.

[35] X.F. Li, D.S. Zhu, X.J. Wang, N. Wang, J.W. Gao, H. Li, Thermal conductivity enhancement dependent $\mathrm{pH}$ and chemical surfactant for $\mathrm{Cu}-\mathrm{H} 2 \mathrm{O}$ nanofluids, Thermochim Acta, 469 (2008) 98-103.

[36] S. Witharana, I. Palabiyik, Z. Musina, Y.L. Ding, Stability of glycol nanofluids - The theory and experiment, Powder Technol., 239 (2013) 72-77.

[37] J. Lee, K. Han, J. Koo, A novel method to evaluate dispersion stability of nanofluids, Int. J. Heat Mass Transf., 70 (2014) 421-429.

[38] D.S. Zhu, X.F. Li, N. Wang, X.J. Wang, J.W. Gao, H. Li, Dispersion behavior and thermal conductivity characteristics of Al2O3-H2O nanofluids, Curr. Appl. Phys., 9 (2009) 131-139.

[39] M. Modak, S.S. Chougule, S.K. Sahu, An Experimental Investigation on Heat Transfer Characteristics of Hot Surface by Using CuO-Water Nanofluids in Circular Jet Impingement Cooling, Journal of Heat Transfer-Transactions of the Asme, 140 (2018).

[40] S. Manjula, S.M. Kumar, A.M. Raichur, G.M. Madhu, R. Suresh, M.A.L.A. Raj, A sedimentation study to optimize the dispersion of alumina nanoparticles in water, Cerâmica, 51 (2005) 121-127.

[41] S. Witharana, C. Hodges, D. Xu, X.J. Lai, Y.L. Ding, Aggregation and settling in aqueous polydisperse alumina nanoparticle suspensions, J. Nanopart. Res., 14 (2012).

[42] D. Lee, J.W. Kim, B.G. Kim, A new parameter to control heat transport in nanofluids: surface charge state of the particle in suspension, J Phys Chem B, 110 (2006) 4323-4328.

[43] Y.Y. Song, H.K.D.H. Bhadeshia, D.W. Suh, Stability of stainless-steel nanoparticle and water mixtures, Powder Technol., 272 (2015) 34-44.

[44] N. Ali, J.A. Teixeira, A. Addali, F. Al-Zubi, E. Shaban, I. Behbehani, The effect of aluminium nanocoating and water $\mathrm{pH}$ value on the wettability behavior of an aluminium surface, Applied Surface Science, 443 (2018) 24-30. 
[45] N. Ali, J.A. Teixeira, A. Addali, M. Saeed, F. Al-Zubi, A. Sedaghat, H. Bahzad, Deposition of Stainless Steel Thin Films: An Electron Beam Physical Vapour Deposition Approach, Materials, 12 (2019) 571.

[46] S. Nanomaterials, Stainless Steel Nanoparticles/ Nanopowder, in, https://ssnano.com/inc/sdetail/stainless_steel_nanoparticles/2760, 2017.

[47] Hach, User Manual - General use pH probe: Models PHC20101, PHC20103

(DOC022.53.80197), in, Hach Company, https://www.hach.com/assetget.download.jsa?id=8027841104, 2013.

[48] Hach, Application note - Temperature Compensation With pH Measurement in, Hach Company, https://www.hach.com/asset-get.download.jsa?id=17525673904, 2013.

[49] I. US Research Nanomaterials, Copper(I) Oxide (Cuprous Oxide) Nanopowder / Cu2O Nanoparticles, in, 2017.

[50] X.W. Ai, J.X. Lin, Y.F. Chang, L.Q. Zhou, X.M. Zhang, G.W. Qin, Phase modification of copper phthalocyanine semiconductor by converting powder to thin film, Applied Surface Science, 428 (2018) 788-792.

[51] P.V. Raleaooa, A. Roodt, G.G. Mhlongo, D.E. Motaung, O.M. Ntwaeaborwa, Analysis of the structure, particle morphology and photoluminescent properties of $\mathrm{ZnS}: \mathrm{Mn} 2+$ nanoparticulate phosphors, Optik, 153 (2018) 31-42.

[52] M. Rabiee, H. Mirzadeh, A. Ataie, Processing of $\mathrm{Cu}-\mathrm{Fe}$ and $\mathrm{Cu}-\mathrm{Fe}-\mathrm{SiC}$ nanocomposites by mechanical alloying, Adv Powder Technol, 28 (2017) 1882-1887.

[53] S. Minaei, M. Haghighi, N. Jodeiri, H. Ajamein, M. Abdollahifar, Urea-nitrates combustion preparation of $\mathrm{CeO} 2$-promoted $\mathrm{CuO} / \mathrm{ZnO} / \mathrm{A} 12 \mathrm{O} 3$ nanocatalyst for fuel cell grade hydrogen production via methanol steam reforming, Adv Powder Technol, 28 (2017) 842853.

[54] B.C. Pak, Y.I. Cho, Hydrodynamic and heat transfer study of dispersed fluids with submicron metallic oxide particles, Exp. Heat Transf., 11 (1998) 151-170.

[55] W.L. Marshall, E.U. Franck, Ion product of water substance, $0-1000{ }^{\circ} \mathrm{C}, 1-10,000$ bars New International Formulation and its background, J. Phys. Chem. Ref. Data, 10 (1981) $295-$ 304. 
2019-06-19

\title{
New pH correlations for stainless steel $316 \mathrm{~L}$, alumina, and copper(I) oxide nanofluids fabricated at controlled sonication temperatures
}

\author{
Ali, Naser \\ Trans Tech Publications
}

Naser A, Amaral Teixeira J, Addali A. (2019) New pH correlations for stainless steel 316L, alumina, and copper(I) oxide nanofluids fabricated at controlled sonication temperatures. Journal of Nano Research, Volume 58, June, 2019, pp.125-138

https://doi.org/10.4028/www.scientific.net/JNanoR.58.125 Downloaded from Cranfield Library Services E-Repository 